\title{
Sobre el valor y el archivo: monedas chilenas y platería mapuche ${ }^{1}$
}

\author{
On Value and Archive: Chilean Coins and \\ Mapuche Jewelry
}

\author{
André Menard \\ Departamento de Antropología, Universidad de Chile. Santiago, Chile. \\ peromenard@gmail.com
}

\section{Resumen}

El artículo plantea una reflexión en torno a la noción de archivo mapuche a partir de la platería entendida como un tipo especial de documento. Debido a que dicha platería está hecha con monedas, se analiza el problema del valor asociado a las piezas. Se describe así el movimiento histórico por el cual las monedas fueron, primero, sustraídas de la lógica que les daba el archivo político-económico chileno para, posteriormente, ingresar en una lógica mapuche del valor y del archivo en tanto instrumento de legitimidad política. Se aborda luego el destino de estas monedas tras la llamada "Pacificación de la Araucanía" y su consecuente reinserción en el ámbito chileno como objetos de mercado hasta sus resignificaciones museográficas actuales. Finalmente, se analizan algunas formas de su valoración actual en el marco de una gestión multicultural y patrimonial de las diferencias culturales.

Palabras clave: platería mapuche, historia mapuche, archivo, monedas, teoría del fetiche.

\section{Abstract}

I propose a reflection on the notion of Mapuche archive focusing on Mapuche jewelry as a special kind of document. As they were made with coins, I analyze the problem of the value associated with these jewels. Thus, I describe a historical movement, through which the coins were first withdrawn from the logic given by the Chilean political-economic archive, and then were inserted in a Mapuche logic of value and archive, understanding the latter as an instrument of political legitimacy. Then I analyze their post-conquest (by Chilean State) journey, and their reinsertion in the Chilean field as commodities until their current museographic resignifications. I conclude by commenting some forms of their present assessment in the context of multicultural and patrimonial management of cultural differences.

Keywords: Mapuche jewelry, Mapuche history, archive, coins, theory of the fetish

1 El presente artículo se enmarca en el proyecto Fondecyt 1140921 "Estudio del sentido, uso y circulación de categorías mágico-carismáticas en los discursos antropológicos y políticos referidos al mundo mapuche en Chile entre 1880 y el presente". 


\section{Introducción}

Quisiera retomar una discusión sobre lo que se puede entender por archivo mapuche. En otros trabajos he entregado una definición operacional del archivo, basada en una noción amplia de la escritura y el registro, una en la que estos no se restringen al ámbito de las escrituras alfabéticas. De ese modo, se han podido reconocer como formas del registro administradas por este archivo mapuche no solo las cartas y tratados atesorados por los caciques y sus secretarías (Pavez, Vezub), sino que también objetos heterogéneos, como los nombres propios o los uniformes militares, los que tenían -al igual que los documentos escritos- la función política de registrar actos de alianza y constituir verdaderas materializaciones de la autoridad, el carisma o el prestigio. En este marco, se puede entender el proceso de conquista militar de los territorios mapuche a fines del siglo XIX en tanto un proceso de instalación por la fuerza de formas estatales y republicanas del archivo que se establecen sobre un territorio delineado por sus propias formas del archivo, y no sobre un espacio virgen de archivos y escrituras. ${ }^{1}$

Por tanto, la noción propuesta comprende un archivo como aquello que otorga legibilidad y eficacia -jurídica, política, económica- a ciertos registros y no a otros (Menard, "Manuel Aburto" xxiv y ss.). Sin embargo, esta noción plantea un problema teórico que me interesa explorar en el presente trabajo. Y es que el archivo así definido puede entenderse bajo categorías clásicas como las de cultura, cosmovisión o estructura en la medida en que todas ellas suponen que el valor de los registros (escrituras, palabras, fetiches, etc.) excede a su materialidad inmediata y remite a un afuera, a un sistema de relaciones (sociales, simbólicas) que serían las que, en definitiva, determinan su valor, su sentido o su eficacia. Es aquí donde la platería mapuche abre un cuestionamiento a estas interpretaciones por el hecho de apuntar a la dimensión material del registro, es decir, a que los registros sean inseparables de su calidad de cosas que reclaman una valoración en sí mismas. De ahí que la platería permita entender estas otras formas del archivo desde el punto de vista de los mecanismos mediante los que articula esta doble forma de entender el valor de los registros en tanto cosas: por un lado, el valor como producto de un sistema que los sostiene, y por otro, el del valor como una propiedad o un contenido en la cosa misma. Esto porque la platería en su constitución tanto histórica como material remite al dinero, objeto o documento muy particular por encarnar más que ningún otro esta problemática del valor.

1 Así, mientras el archivo mapuche, ante la ausencia de un poder soberano que monopolizara el legítimo uso de violencia, se orientaba al registro de las alianzas como índices de una producción política de la paz, el archivo estatal instalado por el Estado chileno, se orientará más bien al registro de las filiaciones, como índices de una identidades fijas y naturalmente dadas. En cierta forma, este archivo se preocupará fundamentalmente de sancionar herencias (biológicas, patrimoniales, económicas, etc.), mientras que el archivo mapuche parece haberse preocupado más bien de sancionar unos devenires o contagios mágicos y carismáticos, como por ejemplo el que tenía lugar a través del pacto entre un cacique y un general chileno o argentino, pacto mediante el cual el cacique entraba en un devenir generalicio, al tiempo que el general entraba en un devenir cacical (Menard, "Archivo y reducto" 325). 


\section{Las monedas en el archivo mapuche}

En la literatura sobre el tema se plantea que "el momento de mayor enriquecimiento de la platería" mapuche ocurrió a partir de la segunda mitad del siglo XIX (Flores 830), y esto se asocia a varios factores. En primer lugar, factores político-económicos vinculados con el desarrollo de la ganadería desde fines del siglo xviII y la consecuente acumulación de riqueza y poder por ciertas jefaturas, lo que se habría traducido en formas de jerarquización social donde la acumulación de joyas habría servido como una forma de signo. Asimismo, este despliegue ganadero habría fomentado un intenso comercio entre la sociedad mapuche y las sociedades chilena y argentina, lo que habría implicado un incremento del circulante en monedas de plata en territorio mapuche y, con ello, de la materia prima de estas mismas joyas. En segundo lugar, está el hito político-numismático de la adopción en el gobierno de Manuel Bulnes del sistema métrico decimal, que también aumentó la circulación de monedas de plata de distinta numeración, pues se comenzaron a acuñar cinco nuevas clases de monedas (Flores 837).

En este contexto de autonomía política y prosperidad económica de la sociedad mapuche, las monedas experimentarán un destino particular. Como bien los señalara Claude Gay, a mediados del siglo xIx, "los indios reciben plata chilena, pero no la intercambian más, guardan esta plata para hacerse espuelas y ornamentos" (cit. en Flores 836). En términos de Marx, se puede decir que las monedas al ser sustraídas de la circulación carecían de la vida propia del dinero -la de circular-, que es lo mismo que sostener que su vida se resume en significar otra cosa. Por el contrario, al entrar en la economía política mapuche, las monedas accedían a otra forma de vida, más bien a la vitalidad museográfica de la reliquia o de todo aquello que adquiere valor, justamente, por sustraerse al intercambio económico o simbólico. ${ }^{2}$ Se generaban así atesoramientos de monedas por parte de los caciques con el fin de confeccionar verdaderas colecciones de platería propias (Morris, Los plateros 52). A causa de este fenómeno, el viajero E. R. Smith constataba también a mediados del siglo XIX "que siempre hay escasez de sencillo en todas las provincias fronterizas" (cit. en Flores 836). Se podría decir que las monedas al convertirse en partes de las joyas, o bien al martillarlas o fundirlas y volverlas materia prima de las mismas, se les sustraía de la lógica

2 Basamos esta oposición entre vida y vitalidad en la tesis de Marc Augé según la cual para una conciencia viva lo verdaderamente sobrenatural, lo impensable es la materia inerte. De ahí que por ejemplo un cadáver sin vida pueda tener más vitalidad que los vivientes que lo rodean. La vitalidad del objeto es, entonces, correlativa de su sustracción respecto de un plano cotidiano, sea este el de la vida, o desde otras perspectivas, del plano de la común de la circulación y el intercambio como lo han descrito Annette B. Wiener al identificar la fuerza y el rol de las "posesiones inalienables" o Maurice Godelier al explicar el carácter sagrado de ciertos objetos baruya sustraídos a la lógica del intercambio. Jean Bazin irá más lejos y en este mismo sentido explicará la fuerza de los fetiche africanos por su sustracción no solo del intercambio económico, sino que de toda función simbólica, esto pues entiende al fetiche como aquello que se sustrae a los códigos que determinan su uso (incluido su uso semiótico como símbolo de otra cosa) (Bazin, Des clous 527). 
del archivo político-económico chileno, y se las integraba en otra lógica de archivo: una en la que el valor no dependía exclusivamente -aunque en las monedas de plata y en el dinero en general antes de los acuerdos de Bretton Woods y su abandono del patrón oro, nunca dejó de estar presente- de su valor simbólico e intercambiario, sino que de su preciosidad intrínseca.

Pero dicho esto, y a diferencia quizás de otros registros de este archivo mapuche - como cartas, nombres o uniformes-, las joyas arrastraban ya cierta dimensión intercambiaria, cierto valor de cambio. De hecho, Guevara habla de las joyas - al menos entre los hombres- en tanto un capital de los caciques que, junto con el ganado o las mantas, podían funcionar como objetos de pago. ${ }^{3}$ Pero en el caso de las joyas, esta dimensión es, al parecer, más persistente, ya que por ejemplo en el mismo término llankatu con que se designa un tipo de collar hecho de cuentas de plata, proviene del término llanka que remite a un tipo de piedra cargada de ciertas potencias, con la que -junto con chaquiras y cuentas de vidrio- se confeccionaban las joyas mapuche antes de la llegada de las monedas de plata. ${ }^{4}$ Lo interesante de las llanka es que sabemos que, desde los tiempos coloniales, sirvieron como formas de pago de ciertos agravios, como por ejemplo las muertes (Rosales 133-4; Augusta 127). Las llanka se integraban así en sistemas judiciales mapuche que -como lo señala, entre otros, Parentini- incorporaron al ganado en el período del auge ganaderos de fines del XVIII y siglo XIX, como objetos de pago, no solo de agravios, sino que también, por ejemplo, de alianzas matrimoniales. Pero claro, llanka y vacas no llegaron nunca al nivel de abstracción del valor de cambio monetario, en la medida en que su intercambio no lograba producir, como lo hace el dinero, el descompromiso de los actores del intercambio (Anspach 56-9), o en términos de Esposito (2003), su inmunización respecto de una comunidad. En otras palabras, la llanka no dejaba nunca de contener la identidad de la víctima o de la novia, así como tambiém de la relación que vinculaba a los intercambiantes (cosa que no ocurre con nuestro dinero que permite objetivar la relación entre quienes intercambian fuera de sus identidades personales). Esto explica que tanto la llanka como la joya de plata no se agotaban en significar un valor en el intercambio, más bien retenían el valor intrínseco de su preciosura, o en otros términos, el valor o la vitalidad singular de su propia historia (lo que no la distingue mucho del valor de autenticidad, por ejemplo, de las obras de arte en nuestros museos). ${ }^{5}$ En otras palabras,

3 En palabras de Tomás Guevara: "Los araucanos han manifestado siempre una marcada predilección por los adornos de plata; las mujeres porque con ellos realzan los atractivos de su sexo i porque es indispensable presentarse en público ataviadas en las condiciones que corresponde a sus familias. En los hombres la posesión de objetos de plata significaba un capital de reserva para el cambio de especies, para regalos de bodas, para pagar los perjuicios por delitos i hasta para completar la cantidad que exijía a la adquisición matrimonial" (Guevara 275).

4 Es lo que señala Tomás Guevara: "Los cintillos de plata con una serie de monedas limadas, es una alhaja araucana que ha reemplazado a las antiguas bandas frontales de piedrecillas azules o de cuentas de vidrios, de que hablan los cronistas. Es una pieza de uso mui corriente entre los indígenas, quienes las llevan indistintamente en la parte alta de la frente, en el cuello o en el pecho" (Guevara 280).

5 Nos remitimos aquí nuevamente a las tesis de Jean Bazin, cuando equipara la potencia de un fetiche africano ( $n k i s i)$ a la de, por ejemplo, una obra de arte como la Mona Lisa, en la medida en que en ambos casos esta potencia no 
se puede decir que tanto llanka como joyas no se agotaban en significar el poder o la riqueza de su poseedor: encarnaban este poder y esta riqueza, eran el agente que los producía. Esto puede explicar que así como los caciques del siglo XIX atesoraban monedas, la arqueología sospecha un atesoramiento análogo y anterior de las llanka (Campbell 640). Valor o vitalidad mágica de la joya, dirán algunos, que para este caso puede traducirse como vitalidad política. Y de esta forma se puede entender a la joya como un documento más en el archivo, que junto con cartas, nombres y uniformes constituían ese cúmulo de objetos cargados de historia y singularidad sobre el cual se sostenían las legitimidades y poderes en la Araucanía independiente. ${ }^{6}$

\section{Las joyas en los archivos chilenos}

Toda la literatura concuerda en que la decadencia de la platería mapuche coincidió con la derrota militar sufrida a fines del siglo xIx. La pérdida de la autonomía territorial, así como el empobrecimiento consecuente habría implicado, por un lado, la disolución de los referentes políticos y simbólicos que sostenían el trabajo de los plateros; pero también - producto del empobrecimiento- la pérdida de su materia prima. En este contexto, vemos cómo se inicia no solo una pérdida de la práctica sino que también de la posesión de estas joyas en manos mapuche. Sabido es su destino como objetos de pago o de empeño (Joseph 9; Flores 843-8), que puede ser leído como una inversión del proceso por el cual, vueltas joyas mapuche, las monedas fueron sustraídas del archivo político-económico chileno. Así, vendidas o empeñadas, las monedas -ahora, joyas- son devueltas al mercado chileno y allí comercializadas en el circuito general de las mercancías. Las que no son fundidas, entran a engrosar las colecciones privadas de anticuarios y coleccionistas. Este proceso coincidió con el surgimiento de un enunciado que fue recurrente hasta la década de los ochenta del siglo xx, a saber, el fin inexorable de la platería mapuche como arte o artesanía. ${ }^{7}$ Aldunate describe este proceso refiriéndose al destino de los retrafe o plateros, quienes, de depender de un longko, pasaron a funcionar como artesanos independientes, incorporados al

depende de la capacidad representacional del objeto - de un espíritu, una cosmovisión, un período o el genio de un artista- sino que de su autenticidad, es decir, de su singularidad material así como de su historia particular (493-520).

6 Para un desarrollo de esta dimensión política del archivo mapuche como talismán, ver Menard, "El archivo, el talismán, el carisma".

7 En este sentido Joseph sostenía que: "Estas formas interesantes desaparecerán con los viejos mapuches. La juventud araucana abandona el traje nacional y adopta los usos de la vida moderna. Los plateros trabajan menos; los veteranos del arte mueren y no son reemplazados. Los profesionales de hoy son escasos y su preparación parece muy inferior a la de sus mayores. La aparición, en las colecciones del norte, de objetos imitados de los indígenas y fabricados para la venta, hace temer que en pocos años más sea difícil estudiar la verdadera platería araucana. Por estos motivos sería de desear un estudio más amplio sobre esta materia" (Joseph 158). Por su parte, Aldunate, medio siglo más tarde planteaba que: "Los plateros han desaparecido, a pesar de los esfuerzos de algunas instituciones por salvar esta artesanía la que, indiscutiblemente y en las actuales condiciones, está condenada a desaparecer" (Aldunate 14). 
mercado artesanal. De allí en adelante estos habrían cobrado por las piezas el doble de su valor en plata: la mitad era utilizada para la pieza misma y la otra funcionaba como pago directamente monetario. A esto se sumaba el hecho de que estas joyas eran vendidas a un comerciante, quien a su vez las revendía a los mapuche al doble de su valor original (Aldunate 13).

El retrafe e intelectual Juan Painecura entrega otro dato que apunta a esta misma desapropiación mercantil de la producción de las joyas. Explica que muchas de estas comenzaron a ser fabricadas por artesanos chilenos con escoria de las maestranzas ferroviaras - de bajo valor- para ser revendidas a altos precios a los mismos mapuche. Pero es en este proceso donde Painecura identifica la decadencia de la platería mapuche como un devenir artesanía, es decir, como una mercancía desprovista de los significados y códigos que antiguamente regían su creación. De la joya como objeto singular de creación, se pasaría entonces a la mera reproducción artesanal (Painecura 40). Decadencia de las joyas debido a la pérdida de las relaciones y medios de producción mapuche, situación que podemos leer como una pérdida del valor que les daba - pero que a su vez le daban- un archivo mapuche entonces derrotado. ${ }^{8}$

Pero esto no significa que las joyas quedaran en un limbo archivísitico. Desde ese momento ingresan, como ya lo señalé, en las colecciones privadas. De hecho el trabajo de Claude Joseph sobre platería araucana (1928) fue realizado en base a la colección privada de Pedro Doyharçabal. "Lo más digno de verse en Temuco", al decir de las "personas notables que visitan el sur de Chile" (4), según Joseph. Estas joyas adornarán algunos museos a principios del siglo $\mathrm{xx}$, ${ }^{9}$ pero no es sino hasta la década de los ochenta en que constatamos una revisibilización museográfica y académica de las mismas. Siguiendo la genealogía que hace Miguel Chapanoff de los discursos referidos a estas joyas y a las formas de documentarlas y presentarlas en los museos, vemos que, a diferencia de su exhibición meramente formal en las exposiciones de principios del siglo veinte, las que tendrán lugar en la década de los ochenta comienzan a considerar sus dimensiones simbólicas - pero siempre desde un discurso detentado por coleccionistas o antropólogos, y no de plateros o sabios mapuche- y, explícitamente, como una forma de escritura. A su valor comercial como antigüedades -correlativo a sus valores eruditos de historicidad como los subjetivos de antigüedad (Riegl)-, ${ }^{10}$

8 Una ilustración notable de este proceso de desterritorialización de las joyas y sus códigos tras la conquista militar chilena es la que devela Margarita Alvarado en su análisis de los retratos fotográficos de mujeres mapuche realizados por Gustave Millet a fines del siglo xIx. Allí muestra cómo la serie de mujeres fotografiadas, y cuyos retratos constituyeron gran parte del imaginario de lo mapuche postrreduccional, ostentan el mismo juego de joyas: "Millet interviene así directamente una normatividad social y estética instalando sobre estas mujeres joyas de plata que probablemente eran de su propiedad" (Alvarado 23). Esta es otra forma expresar el desfase entre joyas y contexto social denunciado por Painecura, desfase que aquí coincide con un despojo y una separación entre las mujeres mapuche y las joyas, devenidas propiedad del fotógrafo.

9 Chapanoff nos informa, por ejemplo, que muchas piezas fueron adquiridas por el Museo Regional de la Araucanía al momento de su fundación en 1940 (Chapanoff 4).

10 El primero -cuyo surgimiento Riegl asocia al siglo xIX - refiere al valor del objeto dado por representar un lugar único en la cadena de la evolución histórica de la humanidad - de ahí su carácter erudito-; mientras que el segundo 
se le agrega el valor etnográfico otorgado por su inscripción en una cultura y -por qué no- en un archivo mapuche.

¿Pero qué clase de archivo sería este? Para entenderlo debemos volver al problema del valor. Por ejemplo, en el texto del catálogo escrito por Olivares y Quiroz en 1988 para la exposición "Plateros de la Luna" realizada en la Biblioteca Nacional, se sostiene que: "Entre los mapuches, el valor del objeto de plata no reside en su esencia. No posee un valor inherente, en sí mismo. [...] En definitiva son ellas [las joyas] las que otorgan al mapuche un estatus preferencial dentro de la estructura social de su grupo. Así el valor de la plata, no es el valor del metal, es el valor del ornamento" (11). En otras palabras, se trata de un archivo cultural que funciona según una lógica intercambiaria, mediante la cual, desde Locke hasta Lévi-Strauss, se ha insistido en la crítica antifetichista: denunciar las falsas creencias en el valor intrínseco del objeto por oposición a su valor funcional en un sistema de relaciones e intercambios (Weiner 28-36; Bazin 549). Lo interesante es que Morris dice lo mismo, pero refiriéndose al dinero para los mapuche: "Los araucanos no utilizaban el dinero entre ellos, el valor intrínseco de este nada les significaba. La plata tenía otras connotaciones que la hacían valiosa, y por esto la emplearon en la confección de sus adornos ceremoniales" (36).

¿No se podría invertir la afirmación de Morris diciendo que, justamente, los mapuche le devolvían al dinero su valor intrínseco de objeto dotado de un valor de uso ${ }^{11}$ ¿O incluso de una materialidad y de una historia singular que lo sustraía a la función de signo abstracto del intercambio? ${ }^{12}$ Esta tensión es la que constatan Olivares y Quiroz al referirse al uso intercambiario efectivo que tuvieron estas joyas: "Las prendas de plata se transforman en objetos de trueque. De esta manera, se configura un nuevo rol para los objetos de plata. Se transforman en una especie de dinero en las transacciones comerciales. Ciertamente es dinero, pero también es mucho más que eso" (14). En ese "mucho más que eso", suerte de suplemento del valor, es donde reside la pregunta por las formas del valor existentes en un archivo mapuche. ¿Ese "mucho más que eso" remite a un suplemento espiritual o a uno material de la función dinero? Pregunta de raigambre teológica y que tiene que ver justamente con el problema

-que Riegl dice ver nacer a principios del $\mathrm{xx}$-, al valor subjetivo que cualquiera puede otorgarle a un objeto por el hecho de percibir su antigüedad, ese trabajo del tiempo que ha hecho de él una ruina.

11 Esta recuperación del valor de uso de las monedas queda bien ilustrada en la siguiente información que Jaime Flores extrae del texto de Verniory: "A petición de los plateros los mapuche preferían la moneda 'menuda' a las grandes. El ingeniero belga Gustavo Vierniory observa esta situación a propósito de la compre de huevos a los mapuche. Por dos monedas de cinco centavos recibía dos docenas, pero si pagaba con una de diez centavos le daban menos de 20 y agrega: 'Nuestros amigos indios transforman las monedas en dijes y joyas, y para ellos valen más dos piezas de 5 que una de diez" (Flores 837).

12 Podríamos hablar de una versión mapuche de esa "fetichización (no mercantil) del dinero" que R. J. Foster describe en el proceso de introducción del dinero en las sociedades papús de Nueva Guinea. Tras una intensa política de educación monetaria, los funcionarios del Australian Reserve Bank quedaban perplejos por el hecho de que los papús insistían en cambiar los billetes viejos por nuevos, lo que Foster asocia a la práctica de restauración de los colores de sus monedas de conchas tradicionales, y que se explicaría por la importancia de la belleza de la moneda como condición estética y material de su valor (Foster 84-5). 
ya enunciado de las distinciones entre fetichismo, idolatría y verdadera religión, es decir, con cierta pulsión misionera y antropológica por rescatar a los indígenas de la adoración directa del objeto, postulando tras esta adoración aparentemente directa, la existencia un sistema de representación de relaciones o deidades invisibles, lo que resuena con aquella dimensión teológica del dinero y la mercancía en tanto "cosa sensorialmente suprasensible" (Marx 87). Recordemos que para estos autores "el valor del objeto de plata no reside en su esencia", por lo que su "mucho más que eso", es decir, el "sensorialmente suprasensible" de la joya no remite solo a su condición de valor de cambio en un circuito de intercambios comerciales sino que también a su valor simbólico en un circuito de intercambios culturales. ${ }^{13}$

Esto tiene por consecuencia el que, de ser documentos o explícitamente unas formas de escritura, las joyas estén remitiendo a un archivo de carácter metafísico, un archivo espiritual: "Las joyas son un medio de comunicación para su pueblo, pues representan lo fundamental de sus convicciones. Y en ellas están presentes el espíritu de la raza, a la luz de sus concepciones metafísicas, el encuentro simbólico protector de las deidades con su pueblo, los mapuches, los hombres de la tierra" (Morris, Los plateros 31). A mi parecer, más que de un archivo mapuche prerreduccional, se trata del archivo antropológico propio de la ideología multicultural que comienza a emerger justamente en los años en que esta proliferación de exposiciones de platería tienen lugar. ${ }^{14}$

$13 \mathrm{Y}$ aquí seguimos nuevamente a Jean Bazin para ir más allá de la noción de singularidad que, por ejemplo, Kopytoff utiliza a la hora de hablar de aquellos objetos que se sustraen al intercambio y, por lo tanto, a la condición de mercancía. Esto pues para Kopytoff dicha sustracción remitiría a una dimensión cultural que la codifica. Así, singular sería sinónimo de cultural por oposición a mercantil (Kopytoff 99-104). Pero, como ya lo señalamos, para Bazin la singularidad de la cosa (asociada a la autenticidad como su capital de individualidad) implica un poder de sustracción respecto de los mismos códigos culturales, un no remitir a nada más que a sí misma de la cosa (y que así la opone al objeto), por el que incluso intercambiada, no pierde esta potencia (Bazin 547-68).

14 En un texto anterior Morris escribía: "Nuestra opinión final es que la hipótesis enunciada por nosotros al inicio de este trabajo, 'que estos adornos de plata (colgantes) no son un capricho arbitrario del platero, sino que obedecen a profundas motivaciones derivadas de su Ethis [sic] Cultural', es congruente, se puede sostener y fundamentar su planteamiento recurriendo a la bibliografía a nuestro alcance, especialmente aquella referente al estudio de su religiosidad, tradiciones y lo relativo a sus singulares conocimientos antronómicos [sic]" (Morris, Tesoros 110). Contrástese esa posición con la de Guevara en los años veinte: "Raros son los artesanos en objetos de plata que se han dedicado a confeccionar pequeñas figuras humanas [...] No revisten carácter relijioso o de superstición como entre los quichuas los idolillos que representan símbolos lares. Las figurillas araucanas eran simples apéndice de otros objetos i caprichos artísticos" (282). Aquí también es interesante notar cierta paradoja en estas interpretaciones de la platería por las que Morris las sustrae a la arbitrariedad sin sentido del capricho individual. En el texto de 1997, planteaba que "el vínculo esotérico que existe entre las mujeres mapuches, las joyas de plata y las deidades, es un profundo misterio. Arcano indescifrable para nosotros, y nos resultará aún más incomprensible si no aceptamos las fuerzas mágicas que ellos les atribuyen a la plata y a sus joyas" (41). Esta idea del sentido como arcano, es decir, como jeroglífico irreductible de una diferencia cultural, contrasta con los ímpetus hermenéuticos con que al mismo tiempo se permitía la interpretación de las formas de estas joyas, no solo remitiendo a contenidos propiamente mapuche (el número cuatro como significante de la tierra), sino que más allá, a "arquetipos universales", como la representación de la fertilidad mediante la figura femenina (Morris, Los plateros 60; ver también Morris, Tesoros 98). 


\section{Recapitulando}

Recapitulando la historia aquí expuesta, se podría decir que en un primer momento el dinero, bajo la forma de monedas, se volvió joya y de esta manera fue sustraído de la circulación que le imponía la lógica soberana de un archivo chileno. Luego, tras la conquista militar, las joyas fueron reinscritas en esta circulación mercantil chilena, sustrayéndolas del archivo mapuche entonces derrotado. Entraron en colecciones privadas, y así en una invisibilidad correlativa a la oblicua visibilidad política que adquirió el movimiento mapuche en el período de su asociación a los movimientos campesino y partidos políticos chilenos entre las décadas del cincuenta y del ochenta. Es a partir de esos años -años en que comienza a aparecer una nueva forma de demanda étnica mapuche que se irá desligando de los partidos políticos chilenos- que reaparecen en contextos museográficos y en los textos académicos, pero (re)significados según las ya señaladas lógicas antropológicas de un valor cultural inseparable de un sentido espiritual. Aquí el trabajo de Juan Painecura vuelve a ser útil, pues en su clasificación de las distintas funciones de las joyas reconoce tres tipos: las joyas de significación social, por la cual se indicaba la posición parental y territorial de su usuario (su tuwun y su kupalme); la política, por la cual se indicaba su posición en las jerarquías del poder; y por último, la filosófica, que remitía a las concepciones de mundo y las entidades espirituales de una religión mapuche. Agrega que, con la derrota militar y la pérdida de autonomía política, las dos primeras esferas quedaron sin sustento material, lo que explicaría un retraimiento de la joyería mapuche a esta última esfera (Painecura 38). Esto lo plantea Painecura en el marco de un proyecto de reapropiación de los sentidos y códigos de una producción y creación de la platería mapuche en un espacio político de los saberes, un archivo, ya no comercial, académico o museográficamente chileno, sino que histórico y filosóficamente mapuche. ${ }^{15}$

Sin ánimo de impugnar esta lectura, solo me gustaría señalar el riesgo que se corre en el actual contexto de gestión multicultural de las diferencias étnicas, de leer inmediatamente ciertos registros, que pudieron tener una función política en el periodo prerreduccional como significantes espirituales. Lo que corresponde a cierta tendencia moderna a neutralizar la horizontalidad política que pueblos como el mapuche lograron sostener hasta fines del siglo XIX, transformándola en una posición subalterna y asimétrica, que podemos llamar patrimonial y que, de esta forma, codifica sus demandas políticas en términos culturales, demandas que parecen ser inseparables de unos requerimientos fundamentalmente espirituales. ${ }^{16}$

15 Painecura escribe: "En el transcurso del siglo xxı nuestros rüxafe tendrán una formación muy diferente a los de siglos pasados, sin embargo el peso específico seguirá siendo el mismo, el conocimiento de la filosofía mapuche, de su organización social y política antigua a la hora de diseñar y construir joyas, pero lo más importante estará dado por la práctica social-religiosa de los rüxafe en términos personales y colectivos dentro del pueblo mapuche" (Painecura 42).

16 Sobre devenir espiritual del sujeto jurídico-político indígena ver Menard "El culto moderno a los indígenas (o el retorno de los indios espirituales)". 
En este sentido, y para concluir, es notable que en diciembre del año 2001, el mismo en que en Chile se publica el informe de Reparación Histórica y Nuevo Trato y además se aplica por primera vez la Ley Antiterrorista contra dos comuneros mapuche, la Casa de Moneda lanza una nueva moneda de cien pesos. En ella figura una mujer mapuche ataviada con sus joyas. Monedas chilenas vueltas joya mapuche se transforman en el cuño de una moneda chilena. Es decir, se convierten en la imagen con que el Estado transforma a la moneda en el significante "sensiblemente suprasensible” de la confianza o del vínculo social impersonal que funda su soberanía. Así, las joyas, después de haber implicado - mediante la recuperación de la irreductible materialidad de las monedas y su inscripción en un archivo mapuche- la suspensión del orden soberano chileno, pasan a ser significantes abstractos del mismo. En cierta forma se podría decir que la entrada de la mujer mapuche con sus joyas en ese cuño consagra aquello que se proclamaba en esas exposiciones de los años ochenta: el integrar a las joyas en el tesoro patrimonial de la nación. ${ }^{17}$ Recordemos que el año 1988, Olivares y Quiroz escribían:

los motivos de quienes las reunieron [las colecciones privadas de platería facilitadas para dicha exposición] se sustentan en una admiración atávica del otro, del indígena y de sus creaciones, lo que obliga a resguardar lo bello, los ornamentos de plata. Es la recuperación de lo notable y su legado, a pesar de la ausencia de sus creadores y propietarios originales. No olvidemos que lo notable forma parte de nuestro patrimonio. Entonces, es también lo mío (19).

Como bien lo señalan estos autores, esta patrimonialización implica la muerte o al menos la ausencia de "sus creadores y propietarios originales", ausencia que más que física, puede estar remitiendo a la ausencia del mapuche como actor -ya no cultural o espiritual- sino que político, mediante su reubicación en el lugar de un objeto de gestión y atesoramiento patrimonial. Desde esta lógica, una mapuche en la moneda siempre será mejor que una mapuche en La Moneda o, peor aún, en su moneda/Moneda.

17 Que esta acuñación se haya realizado en el contexto ideológico del multiculturalismo las vuelve no solo medida del patrimonio nacional, sino que de un patrimonio aun más abstracto y global: aparecen como una medida de la inconmensurable diversidad cultural de la humanidad. Vulnerable diversidad cultural que la razón UNESCiana ha vuelto patrimonio de la humanidad y de la que cada nación debe asegurar, como con todo capital, la conservación y el fomento. De ahí que podamos decir que en la moneda de cien pesos Chile señala su capitalización nacional de este capital global y abstracto de diversidad cultural. 


\section{Agradecimientos}

Quisiera agradecer a Miguel Chapanoff por su invaluable ayuda y generosidad en este acercamiento a la platería mapuche. También a los kimche Juan Painecura, Domingo Coliqueo, Rosendo Huisca, Juan Ñanculef y José Quidel, por permitirme participar de sus conversaciones sobre el tema, y a Susana Chacana y María José Rodríguez del Museo Regional de la Araucanía por todo su apoyo y colaboración. Agradezco también a los revisores de este artículo por sus comentarios y sugerencias.

\section{Bibliografía}

Aldunate, Carlos. "Reflexiones acerca de la platería mapuche”. Platería Araucana. Ed. C. Aldunate y W. Reccius. Santiago, Museo Chileno de Arte Precolombino, 1983, pp. 10-14.

Alvarado, Margarita. "Pose y montaje en la fotografía mapuche. Retrato fotográfico, representación en identidad". Mapuche. Fotografías siglo XIX y XX. Construcción y montaje de un imaginario. Ed. Alvarado, M, P. Mege y C. Báez. Santiago, Pehuén, 2001, pp. 13-27.

Anspach, Mark Rogin. "Les fondements rituels de la transaction monétaire ou comment remercier un bourreau". La monnaie souveraine. Ed. Aglietta, M. y A. Orléan. Paris, Odile Jacob, 1998, pp. 53-83.

Augé, Marc. Dios como objeto. Barcelona, Gedisa, 1998.

Augusta, Félix. José de. Diccionario Mapuche-Español. Santiago, Imprenta Universitaria, 1916.

Bazin, Jean. Des clous dans la Joconde. Toulouse, Anacharsis, 2008.

Campbell, Roberto. "Entre el Vergel y la platería mapuche: el trabajo de metales en la araucanía poscontacto (1550-1850 d.c.)". Chungará, vol. 47, n 4, 2015, pp. 621-644.

Chapanoff, Miguel., "Documentación etnográfica de una colección de platería mapuche: Itinerario de interpretaciones, circulaciones y metáforas en torno a los objetos. Notas etnográficas", 2014, texto inédito.

Esposito, Roberto. Communitas. Origen y destino de la comunidad. Buenos Aires, Amorrortu, 2003.

Flores, Jaime., "La ocupación de la Araucanía y la pérdida de la platería en manos mapuches. Finales del siglo XIX y primeras décadas del XX”. Revista de Indias. vol. 73, no 259, 2013, pp. 825-854.

Foster, Robert J., "Your Money, Our Money, the Government's Money: Finance and Fetishism in Melanesia". Border fetishisms. P. Spyer, editor. Material Objects in Unstable Spaces. Londres, Routledge, 1998, pp. 60-90.

Godelier, Maurice. L'Enigme du don. Paris, Flammarion, 1996.

Guevara, Tomás. Historia de Chile Prehispano. Santiago de Chile, Balcells, 1929. 
Joseph, Claude., "La platería araucana”. Anales de la Universidad de Chile, n², 1928, pp. 1-42.

Kopytoff, Igor. "La biografía cultural de las cosas". La vida social de las cosas. A. Appadurai, editor. México DF, Grijalbo, 1991, pp. 89-122.

Marx, Karl. El Capital, Tomo I/1. México, Siglo xxi, 1975.

Menard, André. "Archivo y reducto. Sobre la inscripción de lo mapuche en Chile y Argentina". Revista de Antropología Iberoamericana, no 3, 2011, pp. 315-339.

---. "El archivo, el talismán, el carisma: Manuel Aburto y el archivo mapuche". Escrituras Americanas, $\mathrm{n}^{\circ}$ 1, 2012, pp. 53-62.

---. "Manuel Aburto Panguilef y los archivos de la Federación Araucana (estudio preliminar)". Libro diario del Presidente de la Federación Araucana, Manuel Aburto Panguilef (1940-1951). M. Aburto Panguilef. Santiago, CoLibris, 2013, pp. XI-CXXIX.

---. "El culto moderno a los indígenas (o el retorno de los indios espirituales)". E. Radiszcz, editor. Malestar y destinos del malestar. Políticas de la desdicha, vol. 1. Santiago de Chile, Social-Ediciones, 2016, pp. 197-207.

Morris, Raúl. Tesoros de la Araucania. Coleccion Raul Morris von Bennewitz. Los Pinpines colgantes de plata de las Joyas mapuches. Los Ángeles, Municipalidad de Los Ángeles/Museo regional de la Araucanía, 1986.

---. Los plateros de la Frontera y la Platería Araucana. Temuco, ufro, 1997.

Olivares, Juan Carlos y Daniel Quiroz. Plateros de la luna. Santiago, Biblioteca Nacional, 1988.

Painecura, Juan. Charu. Sociedad y Cosmovisión en la platería mapuche. Temuco, Ediciones Universidad Católica de Temuco, 2011.

Parentini, Luís. “¿Delincuencia o malones? La justicia no comprendida”. Revista de humanidades, nº. 5, 1999, pp. 127-138.

Pavez Jorge. Cartas Mapuche. Siglo XIX, Santiago, CoLibris-Ocho Libros, 2008.

Riegl, Aloïs. El culto moderno a los monumentos. Caracteres y origen. Madrid, Visor, 1987.

Rosales, Diego de. Historia general del Reino de Chile. Flandes Indiano, Tomo 1. Santiago, Universitaria, 1988.

Vezub, Julio. Valentín Saygüeque y la Gobernación Indígena de las Manzanas, Buenos Aires, Prometeo, 2009.

Weiner, Annette B. Inalienable Possessions. The Paradox of Keeping-While-Giving. Berkeley, University of California Press, 1992. 